\title{
Estudo Comparativo entre Silagem de Milho e Cana Taquara na Alimentação Suplementar de Vacas Leiteiras
}

\author{
W. R. JARDIM, A. MENDES PETXOTO e \\ S. SILVEIRA FILHO
}

5." Cadeira - Escola Superior de Agricultura "Luiz de Queiroz" - Universidade de São Paulo

\section{INDICE}

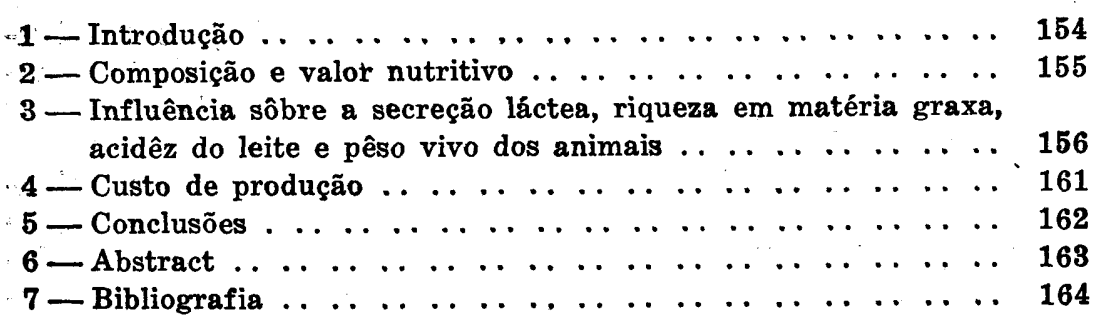




\section{1 - INTRODUÇÃO}

Durante os meses de agosto, setembro e outubro de 1950 , realizámos o presente ensaio, tendo por objetivo comparar a cana taquara (Saccharum sinensis, Roxb) com silagem de milho (Zea mays, Linn.), como suplementos volumosos na alimentação de vacas leiteiras durante a sêca.

Em 1949, foi constatado (1) que, na região de Piracicaba, todos os produtores de leite localizados nas vizinhanças da cidade, utilizavam cana na alimentação suplementar de seus animais e que $37 \%$ dos produtores da zona rural lançavam mão do mesmo recurso. Nessa ocasião verificou-se a inexistência de silos de qualquer tipo, portanto completo desinterêsse pelo emprêgo da silagem.

Considerando as reais vantagens da utilização da silagern na alimentação do gado leiteiro, principalmente durante a sêca, resolvemos compará-la com a cana de açúcar, para verificarmoş se a popularidade desta na região se apoiava em atributos vantajosos ou se era apenas resultante da tradição, aliada ao desconhecimento da silagem como alimento de bôa qualidade e fácil obtenção.

Sob um rápido exame, a cana revela algumas qualidades interessantes, tais como: a) conservar-se verde durante a época de sêca; b) ser de cultura fácil; c) produzir grande massa, isto é, um hectare rende em média por corte, 40 toneladas de cana forrageira ou 12 toneladas de pontas; d) constituir forragem verde suculenta e palatável; e) nas usinas e engenhos, as pontas são sobras e, como o corte coincide com a sêca, o seu emprêgo na alimentação dos animais é baratíssimo.

Por outro lado, a silagem, principalmente de milho, é um alimento aquoso de bôa qualidade, palatável, de fácil obtenção e que pode estar à disposição do criador em qualquer época do ano. E' especialmente indicada para vacas leiteiras, quando a forragem volumosa é um tanto pobre, como acontece em nosso meio durante a sêca. Empregando-se silos simples, de construção barata e contando-se com uma produção média de 15 toneladas de milho por hectare, pode-se obter êste suplemento por preço razoável.

Tratando-se, pois, de dois volumosos altamente convenientes para a alimentação suplementar nos períodos de escassez de pastos, isto é, a silagem de milho, já consagrada pelos criado. res norte-americanos e a cana, tão popular nas fazendas paulistas, julgamos útil confronta-los nos seguintes pontos: a) 
Composição e valor nutritivo; b) Influência sôbre a secreção láctea, riqueza em matéria graxa, acidez do leite e pêso vivo dos animais; c) Custo de produção.

\section{2 - COMPOSIÇÃO E VALOR NUTRITIVO}

Segundo análises realizadas no laboratório da $5 .^{2}$ cadeira pelo Dr. Celso Lemaire de' Moraes, fazendo nove determinações em amostras diferentes de silagem proveniente de um silo cilíndrico subterrâneo e, dôze, em amostras de cana picada, a composição média das citadas forragens, em princípios nutritivos brutos, é a seguinte :

Silagem de milho

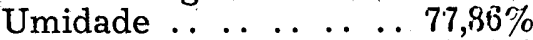

M. Sêca $\ldots \ldots \ldots \ldots$. . . $22,13 \%$

Proteinas ... . . . . . $1.18 \%$

M. Graxa . . . . . . . .

Fibras ..........

E. N. Nitrog. . . . . 11,86\%

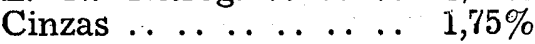

Cana taquara

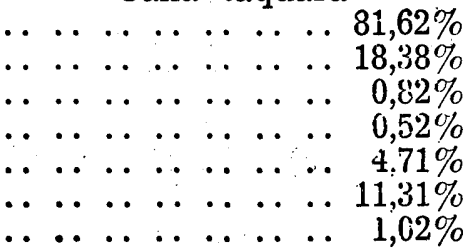

Aplicando os coeficientes de digestibilidade dados por KOK (2) e por GORDON (3), aos elementos orgânicos revelados pelas análises químicas, respectivamente da silagem e da cana, teremos a composição das duas forragens em nutrientes digestíveis e os respectivos valores nutritivos, assim :

\begin{tabular}{|c|c|c|c|c|c|c|}
\hline \multirow[b]{2}{*}{ Nutrientes } & \multicolumn{3}{|c|}{ Silagem de milho } & \multicolumn{3}{|c|}{ Cana taquara } \\
\hline & 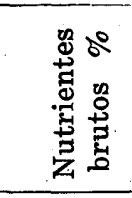 & 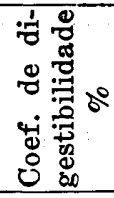 & 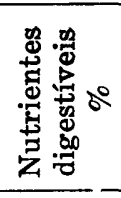 & 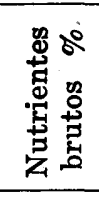 & 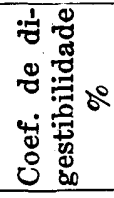 & 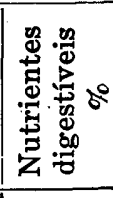 \\
\hline Proteina & $1 ; 18$ & 50 & 0,59 & 0,82 & 57 & 0,46 \\
\hline M. Graxa & 0,82 & 65 & 0,53 & 0,52 & 51 & 0,27 \\
\hline Fibras & 6,55 & 71 & 4,65 & 4,71 & 60 & 2,83 \\
\hline E. N. Nit. & 11,86 & 61 & 7,23 & 11,31 & 63 & 7,13 \\
\hline
\end{tabular}


Em confronto com as análises dadas por MORRISON (4), a silagem de milho revela baixo valor nutritivo e relação nutritiva muito larga, o que se pode atribuir à pequena quantidade de espigas e às perdas ocorridas durante a sua preparação, mas, em compensação, a cana também se apresenta um tanto pobre em matéria sêca.

\section{3 - INFLUÊNCIA SÔBRE A SECREÇÃO LACTEA, RIQUEZA EM MATÉRIA GRAXA, ACIDÉZ DO LEITE E PESO VIVO DOS ANIMAIS}

A influência dos suplementos volumosos, cana taquara e silagem de milho, sôbre a secreção láctea, riqueza em matéria graxa e acidez do leite, e pêso vivo dos animais, foi estudada através de um ensaio de alimentação iniciado a 3-8-1950, e encerrado a 23-10-1950.

\section{a) Material e método}

O ensaio de alimentação foi realizado com vacas da raça Holandêsa malhada de preto, pertencentes ao Pôsto Zootécnico, anexo à Escola Superior de Agricultura "Luiz de Queiroz".

O regime de criação empregado é o de meia estabulação, isto é, as vacas passam as horas mais quentes do dia aorigadas no estábulo, saindo apenas às 4 e 30 horas da tarde para o pasto, onde pernoitam. São recolhidas no dia seguinte às $6 ?$ 30 horas, para a primeira ordenha, durante a qual thes é ministrada uma ração de farelos (concentrados).

Os animais foram separados em 2 lotes, A e B, com 6 vacas cada um. Ambos os lotes receberam a mesma ração básica de farelos, durante todo o decorrer do ensaio, apenas variando o suplemento volumoso.

A ração básica empregada foi calculada segundo o método aconselhado por MORRISON (4). De acôrdo com o mesmo, conforme a natureza e qualidade das pastagens de que os animais dispõem, é estabelecida a porcentagem de proteina digestível a ser fornecida pela mistura de farelos. Os pastos do Pôsto Zootécnico podem ser considerados como médios, pois são constituidos de gramíneas, principalmente capim catingueiro, e suplementados por outras gramíneas cortadas (capins jaraguá, fino, elefante, etc.) na época das águas, e por cana, silagem ou mandioca, no periodo de sêca. Segundo o método citado, os animais, nessas condições, precisam receber uma ração básica com 15 a $18 \%$ de proteina digestível. 
Eis a ração fornecida, calculada na base de $100 \mathrm{~kg}$.

$\begin{array}{lr}\text { Milho desintegrado A } & 40 \mathrm{~kg} . \\ \text { Farelo grosso de trigo } & 25 \mathrm{~kg} . \\ \text { Farelo de Refinazil } & 15 \mathrm{~kg} . \\ \text { Farelo de Amendoim } & 5 \mathrm{~kg} . \\ \text { Farelo de Algodão } & 15 \mathrm{~kg} \text {. } \\ \text { Mistura mineral }-3 \mathrm{~kg} \text {. cada } 100 \mathrm{~kg} \text { cla mistura }\end{array}$

A distribuição dessa mistura de farelos foi realizada cie acôrdo com a produção de leite, seguindo-se aproximadamente êste criterío: - $1 \mathrm{~kg}$. de mistura por cabeça e por dia, para cada $3 \mathrm{~kg}$. de leite produzido. A mistura mineral empregada é formada por 1 parte de pedra calcárea, 1 de farinha de ossos, 1 de sal e, ás vezes, 20 a 30 gramas de iodeto de potássio, para cada 100 partes daquele suplemento mineral.

A suplementação de volumosos foi realizada, fornecendose $15 \mathrm{~kg}$. de cana taquara picada ou silagem de milho, por cabeça e por dia. A quantidade inicial foi de $5 \mathrm{~kg}$., aumentandose gradativamente durante uma semana nos períodos de transição.

A cana picada e o milho, da variedade Santa Rosa, foram fornecidos pela Fazenda Modêlo, anexa à Escola, e a silagem preparada em um silo cilindrico subterrâneo do Pôsto Zootécnico. A distribuição dos volumosos foi realizada em duas refeições : a 1a., aproximadamente às 8 horas, e a $2 a$., às 14 e 30 horas.

\section{b) Plano da experiência}

O ensaio incluiu 6 períodos assim distribuidos:

a) $10^{\circ}$ periodo, preparatório, de uma semana, durante 0 qual os lotes receberam alimentação usual; $2 .^{\circ}$ período, de transição, também com uma semana de duração. Os animais do lote $\mathrm{A}$ começaram a receber silagem e os do lote $\mathrm{B}$ cana picada. Inicialmente a quantidade usada foi de $5 \mathrm{~kg}$., a quel gradativamente foi aumentanda até atingir $15 \mathrm{~kg}$.; c) $3 .^{\circ}$ periodo, de uma semana, quando se procedeu à inversão dos suplementos $15 \mathrm{~kg}$. de silagem e os do lote $\mathrm{B}, 15 \mathrm{~kg}$. de cana; d) $4 .^{\circ}$ período, de uma semana quando se procedeu à inversão dos suplementos volumosos, também de maneira gradativa, até atingir $15 \mathrm{~kg}$. cada um; e) $5 .^{\circ}$ período, de 3 semanas. Aos animais do lote A, forneceram-se $15 \mathrm{~kg}$. de cana picada, e aos do lote $\mathrm{B}, 15 \mathrm{~kg}$. de silagem. Durante êste período, bem como no $3 .^{\circ}$, a distribuição 
dos volumosos foi realizada em duas refeições: $10 \mathrm{~kg}$. pela manhã e $5 \mathrm{~kg}$. à tarde; f) $60^{\circ}$ período, de 2 semanas, em cujo decorrer as vacas voltaram a receber a alimentação usual de antes do início do ensáio, isto é, capim catingueiro cortado, bastante fibroso, em estágio bem posterior à floração.

Os dados que coletámos durante a experiência se referem a : 1) Produção de leite; 2) Porcentagem de matéria graxa no leite; 3) Acidez do leite; 4) Pêso vivo dos animais.

A pesagem do leite produzido foi realizada durante todos os dias do ensaio, enquanto que a determinação da matéria graxa (método de Gerber), acidez e pesagem dos animais, foram feitas sòmente nos três primeiros dias de cada semana.

c) Análise dos resultados

$\mathrm{Na}$ análise da variância procurámos estudar a influência das seguintes causas de variação :

a) Influência da suplementação volumosa;

b) Influência dos períodos considerados (3.o e 5.o);

c) Influência da variação individual;

d) Influência da variação diária, dentro dos períodos.

\section{I - Produção de leite}

Apenas foram analisados os dados obtidos durante o 30 e 5.o períodos, isto é, quando os animais estiveram sob influência da alimentação dos volumosos em estudo. Considerámos também, apenas 5 vacas em cada grupo, visto ter uma delas parido durante o ensáio, prejudicando a coleta dos dados realmente aproveitáveis. Os resultados obtidos constam do quadro seguinte :

\begin{tabular}{|c|c|c|c|c|}
\hline $\begin{array}{c}\text { Fonte de } \\
\text { variação }\end{array}$ & 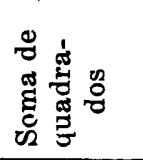 & 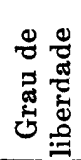 & Variâneıa & Erro \\
\hline $\begin{array}{l}1 \text { Suplementa- } \\
\text { ção volumosa } \\
2 \text { Períodos } \\
3 \text { Individual } \\
4 \text { Diária (den- } \\
\text { tro do per.) } \\
5 \text { Resíduo } \\
\text { Total } \\
\end{array}$ & $\begin{array}{r}1,85 \\
82,28 \\
2.144,76 \\
\\
51,50 \\
66,76 \\
2.347,15\end{array}$ & $\begin{array}{r}1 \\
1 \\
9 \\
40 \\
467 \\
418\end{array}$ & $\begin{array}{r}1.85 \\
82,28 \\
238, \dot{3} 1 \\
1,28 \\
0,18\end{array}$ & $\begin{array}{r}1,36 \\
9,07 \\
15,43 \\
1,13 \\
0,42 \\
\end{array}$ \\
\hline
\end{tabular}




$$
\begin{aligned}
& \text { ข) } 15=3,24 * * * \\
& \text { v25 }=21,59 \\
& \vartheta 35=36,73 \\
& \vartheta 45=2,69 * * *
\end{aligned}
$$

Obs : A significação para os limites de probabilidade de $5 \%, 1 \%$ e $1 \%$ o é indicada respectivamente por um, dois e três asteriscos.

A média diária de produção para as 10 vacas durante o tempo em que receberam suplementação de silagem foi de $\overline{\mathrm{v}}=6,502 \mathrm{~kg}$. de leite, $2,09 \%$ mais elevada que a média observada durante a época de suplementação com cana, .. ... . . $\overline{\mathrm{v}}=6,369 \mathrm{~kg}$. $\mathrm{O} \sigma$ dif. $\overline{\mathrm{v}}$ foi de $0,041 \mathrm{e}$ o " $\delta "=3,24$, altamente significante.

\section{II - Porcentagem de matéria-graxa}

\begin{tabular}{|c|c|c|c|c|}
\hline $\begin{array}{c}\text { Fonte de } \\
\text { variação }\end{array}$ & 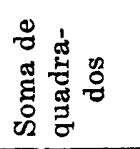 & 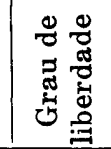 & Variância & Erro \\
\hline \begin{tabular}{ll|}
1 Suplementa- \\
ção volumosa \\
2 Períodos \\
3 Individuai \\
4 Diária (den- \\
tro do per.) \\
5 Residuo \\
Total \\
\end{tabular} & $\begin{array}{r}0,21 \\
0,04 \\
27,17 \\
\\
3,05 \\
22,28 \\
52,75 \\
\end{array}$ & $\begin{array}{r}1 \\
1 \\
9 \\
16 \\
151 \\
178 \\
\end{array}$ & $\begin{array}{l}0.21 \\
0,04 \\
3.02 \\
0.18 \\
0.147\end{array}$ & $\begin{array}{l}0,46 \\
0,20 \\
1,73 \\
\\
0,42 \\
0,38 \\
\end{array}$ \\
\hline & $\begin{array}{l}= \\
= \\
= \\
=\end{array}$ & $\begin{array}{l}1,205 \mathrm{i} \\
1,90 \mathrm{i} \\
4,55 \\
1,105 \mathrm{i}\end{array}$ & $\begin{array}{l}\text { ig. } \\
\text { ig. } \\
\text { ig. }\end{array}$ & \\
\hline
\end{tabular}

Também considerámos apenas os dados referentes ao $3^{\circ}$. e 5.o períodos, sendo cada grupo de 5 vacas. Os resultados obtidos são os seguintes :

Durante a suplementação com silagem, as 10 vacas apresentaram uma porcentagem média diária de $3,922 \%$ de matéria graxa, e durante a alimentação com cana, aquela niédia foi de $3,854 \%$. A diferença entre as médias, de $0,068 \%$, careceu de importância estatística. $\mathrm{O} \sigma$ dif $\mathrm{v}$ foi de 0,057 e $0 \ldots \ldots$. " $\delta "=1,2$, insignificante. 


\section{III - Acidez do leite}

Considerámos apenas 12 determinações, e não 18 como no caso anterior, pois tivemos que desṕrezar as 3 primeiras realizadas, em cada grupo.

\begin{tabular}{|c|c|c|c|c|}
\hline $\begin{array}{c}\text { Fonte de } \\
\text { variação }\end{array}$ & 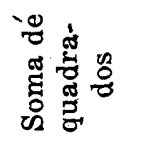 & 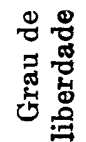 & Variância & Erro \\
\hline $\begin{array}{l}\text { 1 Suplementa- } \\
\text { ção volumosa } \\
2 \text { Períodos } \\
3 \text { Individual } \\
4 \text { Diária (den- }\end{array}$ & $\begin{array}{r}6,30 \\
13,00 \\
147,39\end{array}$ & $\begin{array}{l}1 \\
1 \\
9\end{array}$ & $\begin{array}{r}6,30 \\
13,00 \\
16,37\end{array}$ & $\begin{array}{l}2,51 \\
3,61 \\
4,04\end{array}$ \\
\hline $\begin{array}{c}\text { tro do per.) } \\
\text { Resíduo } \\
\text { Total }\end{array}$ & $\begin{array}{r}43,47 \\
101,59 \\
311,75\end{array}$ & $\begin{array}{r}10 \\
97 \\
118\end{array}$ & $\begin{array}{l}4,35 \\
1,047\end{array}$ & $\begin{array}{l}2,08 \\
1,02 \\
\end{array}$ \\
\hline
\end{tabular}

$$
\begin{aligned}
& \vartheta 15=2,46 * * \\
& \vartheta 25=3,53 * * \\
& \vartheta 35=3,96 * * \\
& \vartheta 45=2,03 * *
\end{aligned}
$$

A média de acidez observada durante a suplementação com silagem foi de 18,40 gráus Dornic, e durante a alimentação com cana, 17,94 graus Dornic. A diferença entre as médias de 0,460 , apresentou um $\sigma$ dif. $\bar{v}=0,18$, sendo $o$ " $\delta "=2,25$ significante ao nível de $1 \%$ de probabilidade.

\section{IV - Pêso vivo dos animais}

$\mathrm{Na}$ coleta dos dados, consideramos 6 animais em cada grupo, pois pudemos incluir duas vacas sêcas. Os resultados obtidos são os seguintes : 


\begin{tabular}{|c|c|c|c|c|}
\hline $\begin{array}{l}\text { Fonte de } \\
\text { variação }\end{array}$ & 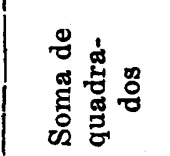 & 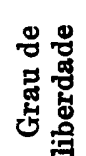 & Variância & Erro \\
\hline $\begin{array}{l}\text { Suplemeita- } \\
\text { ção volumosa } \\
2 \text { Periodos } \\
3 \text { Individual } \\
4 \text { Diária (den- }\end{array}$ & $\begin{array}{r}365,56 \\
900,37 \\
287.968,24\end{array}$ & $\begin{array}{r}1 \\
1 \\
11\end{array}$ & $\begin{array}{r}365.56 \\
900.37 \\
26.178,93\end{array}$ & $\begin{array}{r}19,12 \\
30,01 \\
161,79\end{array}$ \\
\hline $\begin{array}{l}5 \text { tro do per.) } \\
\text { Totalduo } \\
\text { Total }\end{array}$ & $\begin{array}{r}3.130,34 \\
8.310,08 \\
300.674,59\end{array}$ & $\begin{array}{r}16 \\
1005 \\
214\end{array}$ & $\begin{array}{r}195,65 \\
44.92\end{array}$ & $\begin{array}{r}13,98 \\
6,70 \\
\end{array}$ \\
\hline
\end{tabular}

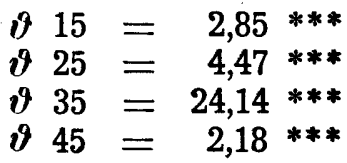

$\mathrm{Na}$ suplementação com cana o pêso vivo médio foi de $\overline{\mathrm{v}}=520,29 \mathrm{~kg}$., $2,61 \mathrm{~kg}$. mais alta que o pêso vivo médio, durante a suplementação com silagem, $\bar{v}=517,68 \mathrm{~kg}$. $O \quad \sigma$ dif. $\overline{\mathrm{v}}$ é de 0,912 e o " $\delta " 2,86$, altamente significante.

\section{4 - CUSTO DE PRODUÇÃO}

Os dados relativos ao custo de prcdução da cana taquara e da silagem de milho nos foram formecidos pela administração da Fazenda Modêlo, anexa à Escola Superior de Agricultura "Luiz de Queiroz".

Podemos considerar os custos da silagem de milho e da cana taquara um pouco onerados pela mão de obra cara, em virtude do melhor salário e do horário de serviço mais reduzido dos operários da Escola, em confronto com trabalhadores de fazendas particulares.

Não obstante, julgamos os dados satisfatórios, porquanto deixamos de computar o custo e depreciação do silo utiuizizàio, assim como no caso da cana consideramos apenas o primeiro corte, cujo rendimento é sempre superior à média final das várias safras. Mesmo assim, esclarecemos que os presentes dados exprimem com bastante aproximação o custo real de produção de ambos os suplementos, nas condições em que foram estudados. 
Damos, a seguir, os dados referentes ao custo de produção da cana e da silagem, tomando por base o rendimento de um alqueire paulista cultivado: $(24.200 \mathrm{~m} 2)$.

\section{Silagem de milho}

1. Preparo do solo

2 Iavras, gradagem e pranchonamento $1.534,58$

2. Semeadura

Sulcagem e plantio simultâneos

Sementes ( $90 \mathrm{~kg}$.

3. Tratos culturais

1 trato com Planet $\mathrm{Jr}$.

4. Colheita

Corte

5. Transporte

6. Carregamento do silo

Total

$95 ; 37$

135,00

254,96

$1.050,00$

704,25

$2.018,52$

Cr\$5.762,98

A produção de milho por alqueire foi de $40.159 \mathrm{~kg}$., fornecendo $34.125 \mathrm{~kg}$. de silagem, descontadas tôdas as perdas (aproximadamente $15 \%$ ). Portanto, o preço da silagem por tonelada atingiu $\operatorname{Cr} \$ 160,00$.

\section{Cana taquara}

1. Preparo do solo

2 lavras e gradagem

2. Semeadura

Sulcagem

Mudas (10 tons.)

Plantio

3. Tratos culturais

Formação com 4 carpas $\quad 1.422,30$

4. Corte

$1.425,00$

5. Transporte

740,00

$1.228,20$

530,00

$1.500,00$

374,50

Total : - Cr $\$ 7.220,00$

A produção foi de $96.000 \mathrm{~kg}$. aproximadamente por alqueire, custando, portanto, a tonelada de cana taquara Cr\$75,20.

\section{5 - CONCLUSO์ES}

1 - Quanto à composição e ao valor nutritivo, a silagem de milho e a cana taquara, pràticamente se equivalem, como leve superioridade da primeira; 
2 - A influência da silagem sôbre a produção de leite das vacas mostrou-se altamente significante do ponto de vista estatístico, com rendimento durante o período em que os animais consumiram aquele volumoso, 2,09\% mais elevado;

3 - Sôbre a riqueza do leite em matéria graxa, não se constatou influência significante de qualquer dos suplementos;

4 - A silagem acarretou acidez mais elevada do leite, que a cana, acusada por 18,40 e 17,94 gráus Dornic, em média, respectivamente, diferença esta significativa ao nível de $1 \%$ de probabilidade;

5 - Sôbre o aumento de pêso dos animais, o efeito da cana foi mais favorável, acarretando um acréscimo médio de $2,61 \mathrm{k}$. por cabeça;

6 - O custo de produção por tonelada somou $\operatorname{Cr} \$ 75,20$ para a cana e Cr $\$ 160,00$ para a silagem de milho, ou sejam 2,12 vezes mais caro para a última. $\mathrm{O}$ preço diário do suplemento volumoso, por cabeça foi de $\operatorname{Cr} \$ 1,13$ e $\operatorname{Cr} \$ 2,40$, para a cana e a silagem respectivamente, acusando uma diferença de Cr\$ 1,27 favorável à cana;

7 - O exame dos dados obtidos revela que a maior produção de leite devida à silagem de milho, não compensa o mais alto custo de produção deste suplemento, quando comparado à cana taquara;

8 - Do ponto de vista econômico é, pois, mais interessante o emprêgo da cana taquara, principalmente se considerarmos que o custo de produção da silagem de milho se mantêm estacionário ou se eleva em anos sucessivos, enquanto que o da cana tende a baixar nos cortes seguintes;

9 - Confrontando ambos os volumosos estudados, os $\mathrm{A}$. A. consideram mais econômico o emprêgo da cana taquara, como suplemento volumoso, principalmente nas zonas canavieiras do país, ressalvando eventuais casos de condições ambientais grandemente desfavoraveis à sua cultura.

\section{6 - ABSTRACT}

The A. A. compare corn silage (Zea mays L.) with sugar cane (Saccharum sinensis Roxb.) in the supplementary feeding of dairy cow. Both the feeds were studied in relation to the following points: composition and nutritive value; influence of milk production, milk fat, milk acidity and body weight; cost of production.

Both corn silage and sugar cane were analysed by ordinary methods, and their digestibility was determined by means of digestibility coefficients; their composition and nutritive value are, practically, equivalent, but silage showed slight superiority. 
The feeding experiment was carried out with two groups of six Holstein Friesian cows each, of the Escola Superior de Agricultura "Luiz de Queiroz" herd. Both groups were fed with the same basic concentrates mixture, calculeted according to MORRISON. During the various periods of the experiment, only the roughage supplement varied.

The supplementary feeding consisted of $15 \mathrm{~kg}$ of chopped sugar cane or corn, silage, per day and per cow, given in two daily meals in the barn. At 4,30 p. m., the cows are set free in the field, where they pass the over night.

The experiment was divided into six periods, in which there was a gradative change of the supplementary feeding between the two groups. The milk was weighed every day; the analysis of milk fat and acidity and the weighing of the animals, were made only on the first three days of every week.

The analysis of data showed that:

a) Milk production was increased significantly by silage feeding;

b) The ri was not any influence on milk fat;

c) The silage caused higher milk acidity;

d) The sugar cane gave a greater increase of body weight.

The cost of production of corn silage was 2,12 time higher, than sugar cane, hence, although the silage gave a higher milk production, its use is not economical, compared with sugar cane, in our conditions.

\section{7 - BIBLIOGRAFIA}

1 - JARDIM, W. R., 1949. Contribuição para o estudo da produção leiteira em nosso meio. Piracicaba. p: 19.

2-KOK, E. A. e GUARAGNA, R. N., 1941. Estudo sôbre silos do tipo "trincheira". Bol. Ind. Animal. Vol. 4, n. 3-4. São Paulo. pp: 151-173.

3-GORDON, F. D. and HURST, W. M., 1937. Artificial drying of forage crops. U. S. Department of Agriculture. Circular 433 - Washington D. C.

4-MORRISON, F. B., 1943. Alimentos y Alimentacion. 20a. ed. Santiago del Chile.

5-BRIEGER, F. G., 1946. Limites unilaterais e bilaterais na Análise Estatística Bragantia. 6. Campinas. pp: 479-545.

6-BRIEGER, F. G., 1937. Tabuas e Fórmulas para Estatística. Comp. Melhoramentos de São Paulo.

7-DELGADO, C. A. e GONZALEZ, A. J., 1942. A criação de gado e a indústria açucareira. A Fazenda, ano 87: n. 8. New York, pp: 288-289 e 292-293. 